Kansas State University Libraries

New Prairie Press

\title{
FITTING BOLE-VOLUME EQUATIONS TO SPATIALLY CORRELATED WITHIN-TREE DATA
}

Timothy G. Gregoire

Oliver Schabenberger

Follow this and additional works at: https://newprairiepress.org/agstatconference

Part of the Agriculture Commons, and the Applied Statistics Commons

\section{(c) (1) $\Theta(9$}

This work is licensed under a Creative Commons Attribution-Noncommercial-No Derivative Works 4.0 License.

\section{Recommended Citation}

Gregoire, Timothy G. and Schabenberger, Oliver (1994). "FITTING BOLE-VOLUME EQUATIONS TO SPATIALLY CORRELATED WITHIN-TREE DATA," Conference on Applied Statistics in Agriculture. https://doi.org/10.4148/2475-7772.1362

This is brought to you for free and open access by the Conferences at New Prairie Press. It has been accepted for inclusion in Conference on Applied Statistics in Agriculture by an authorized administrator of New Prairie Press. For more information, please contact cads@k-state.edu. 


\title{
FITTING BOLE-VOLUME EQUATIONS TO SPATIALLY CORRELATED WITHIN-TREE DATA
}

\author{
Timothy G. Gregoire and Oliver Schabenberger \\ College of Forestry and Wildlife Resources \\ Virginia Polytechnic Institute and State University \\ Blacksburg, Virginia 24061-0324 U. S. A.
}

\begin{abstract}
Equations to predict the volume of an individual tree bole between stump height and the height at which its diameter has tapered to a specified minimum are common in forestry. When fitting such a regression equation, a sample of trees which span the range of sizes needed for eventual application of the equation is selected. Bole diameter is measured at ascending heights on the bole. Each tree, therefore, contributes multiple measurements to the data fitted to the equation. In contrast to past practice, we model these data in a manner which accounts for the likely spatial correlation among measurements within a tree. The resulting mixed-effects nonlinear model is fitted by REML and also by generalized estimating equations (GEE). Results from the two approaches are nearly identical, which suggests that the computationally less demanding GEE may be acceptable as a routine alternative to a fully parameterized approach.
\end{abstract}

Keywords: nonlinear modeling, mixed-effects models, REML, GEE.

\section{Introduction}

When trees are harvested for eventual conversion into wood and fiber products, the felled trees are delimbed and their tips are severed at a point above which the bole diameter is too small to convert to a merchantable product economically. For purposes of forest inventory and planning, it is useful to have bole-volume equations to predict the volume of trees while standing, regardless of whether they eventually will be harvested. Typically, a linear or nonlinear regression model is fitted to a cross-section of trees for this purpose, using stem basal diameter and some measure of stem height as 
covariates with each measure of bole volume. Of course, the merchantable volume of the bole depends, too, on the upper-bole diameter which establishes the merchantability limit. Because this limit varies depending on the anticipated end-use product, it has changed over time in accordance with technological advances in milling and with changing economic value of the raw material.

In the past it has been common practice to fit a new bole-volume equation, as required, in response to changes in the upper-bole merchantability limit. A recent trend has been to include the upper-bole diameter limit as an additional covariate in the volume equation, thereby making it possible to use a single equation to predict merchantable volume to any upper-bole diameter.

To illustrate the modeling task, we have graphed the cumulative volume in two sweetgum (Liquidambar styraciflua L.) trees between stump height to stem tip versus the diameter of the bole, as measured at roughly 3 foot intervals (Figure 1). Even when comparing just these two trees, it is immediately obvious that cumulative volume to a specified upper diameter, say $d$, varies among trees principally due to the differences in their basal diameters, $D$, and stem height, $H$. The modeling task is to adequately express cumulative volume as a function of $d, D$, and $H$. In forestry parlance, $\mathrm{D}$ is known as diameter-at-breast-height, and it is this diameter which is used to compute a tree's basal area, i.e., its cross-sectional area at breast height. Thus, $\mathrm{D}=0$ for a tree shorter than breast height, yet it has finite bole volume.

In Figure 2 we show the empirical volume functions after standardizing both axes to a $0-1$ scale, which serves to emphasize the similarity of cumulative bole volume to cumulative distribution functions in general. While the diameter of a tree bole tapers with increasing height above ground, the taper is neither smooth nor monotonic, and it may vary greatly among trees, again as evidenced by comparing just the two trees shown in the graphs. It is worthwhile to note, too, that these empirical cumulative volume functions display a general sigmoidal shape, which is characteristic of many biological growth functions (Seber and Wild, 1989). Inasmuch as the diameter of a stem at a particular height depends jointly upon stand density and tree age, the interpretation of cumulative volume as a growth curve seems reasonable.

To amplify what was stated above, the goal is to express cumulative bole volume as a smooth curve while allowing for fluctuations within and among trees as much as possible, yet allowing for the curve's applicability to all trees of the species with similar morphological characteristics. The primary objective is to provide an equation to predict the bole volume of a standing tree to a stipulated upper-bole diameter, based on easily obtained measurements of its basal diameter and total height. 


\section{Customary Model}

While forest researchers have fitted a number of equations to date for this purpose, we initially consider the equation presented by Amateis and Burkhart (1987) as an example, because it or slight variations of it appear to be the most commonly used.

$$
\begin{aligned}
\mathrm{V}_{\mathrm{d}} & =\mathrm{E}\left[\mathrm{V}_{\mathrm{d}}\right]+\epsilon \\
& =\mathrm{V}_{0} \mathrm{R}+\epsilon
\end{aligned}
$$

where

$$
\begin{aligned}
\mathrm{V}_{\mathrm{d}} & =\text { bole volume to upper-bole diameter, } d \\
\mathrm{~V}_{0} & =\text { total bole volume } \\
& =\mathrm{b}_{0}+\mathrm{b}_{1} \mathrm{X} \\
\mathrm{R} & =1+\mathrm{b}_{2} d^{\mathrm{b}_{3}} / \mathrm{D}^{\mathrm{b}_{4}} \\
\mathrm{X} & =\mathrm{D}^{2} \mathrm{H}
\end{aligned}
$$

and $\mathrm{D}$ is diameter at breast height (4.5 feet aboveground), $\mathrm{H}$ is height of the tree, as defined earlier.

The expression for total bole volume, $V_{0}$, has had widespread use in forestry. The adjoining term, $\mathrm{R}$, expresses the ratio of merchantable to total bole volume. Its construction ensures that $\mathrm{R}=1$ when $d=0$ at the tree tip, thereby providing that $\mathrm{V}_{\mathrm{d}}=\mathrm{V}_{0}$ at that point.

Typically the two components of $V_{d}$, namely $V_{0}$ and $R$, have been fitted separately. It is reasonable to assume that the joint estimation of its parameters would be more efficient and provide more efficient predictions of $\mathrm{V}_{\mathrm{d}}$. The data to which the model is fitted comprise a selection of, say $n$, trees, each of which is felled and measured at various intervals along the bole. That is, for the $i^{\text {th }}$ tree, $i=1, \ldots, n$, there are $m_{i}$ measurements of bole diameter at various heights along the bole, culminating at the tip. The volume of each bole section is computed and cumulated to provide the volume from ground (or stump height) to the top of the section. The correlation among measurements on the bole has always been ignored, - a fact which provided the impetus to our effort.

A parsimonious way to model within-tree correlation directly is as a continuous autocorrelation, namely

$$
\mathrm{E}\left[\epsilon_{\mathrm{ij}} \epsilon_{\mathrm{ik}}\right]=\sigma^{2} \exp \left(\frac{-\left|\mathrm{S}_{\mathrm{ijk}}\right|}{\rho}\right)
$$


where $\mathrm{S}_{\mathrm{ijk}}$ is some distance metric separating the $\mathrm{j}^{\text {th }}$ and $\mathrm{k}^{\text {th }}$ measurements on the $\mathrm{i}^{\text {th }}$ tree bole, and $\rho$ is the autocorrelation parameter to be estimated. Diggle (1988), among others, has suggested such an approach when observations are unequally spaced, as they are in this setting. While this approach accounts for the likely serial correlation of measurements along the tree bole, the coefficients of the model retain an interpretation in terms of average behavior; i.e. the cumulative volume for an individual tree can be fitted only as precisely, as the tree's taper coincides with the average in the population under scrutiny.

To model an individual tree's growth pattern more closely while retaining generality, an alternative approach is to let one or more of the parameters vary randomly among trees. It is assumed that the effect of the within-tree correlation on the marginal covariance will be adequately modeled by the random effects structure (Lindstrom and Bates, 1990). With the random parameters approach, one allows each subject tree to depart from the population average, essentially fitting the model individually to each tree. Jones (1990) noted that modeling the covariance structure directly or through random parameters indirectly will often be equally effective in accounting for serial correlation among the measurements. Gregoire, Schabenberger, and Barrett (1994) encountered this, too, in an earlier investigation unrelated to the present one.

By assuming one or both parameters of $\mathrm{V}_{0}$ are random, the correlations among observations taken along a tree bole will be a function of $d$, the metameter on which serial correlation likely depends. For this reason, we adopted the random parameters approach in the present work.

\section{Mixed-effects Model}

Starting from the fixed-effects model, (1), we allowed for the possibility that $\mathrm{b}_{0}$, $b_{1}$, or both were random. To account for inflection in the observed trend of cumulative volume, we replaced $R$ in (1) by

$$
\mathrm{R}=\frac{\mathrm{t}^{\beta_{2}}+\left(\beta_{3} \mathrm{t}\right)^{\beta_{2}}}{1+\left(\beta_{3} \mathrm{t}\right)^{\beta_{2}}}
$$

where $t=1-d / D$. This is a particular form of a curve that Seber and Wild (1989) attribute to Morgan et al. (1975), who studied growth response to nutritional uptake. Note that (3) collapses to unity at $d=0$, thereby preserving $\mathrm{V}_{\mathrm{d}}=\mathrm{V}_{0}$ at the tip of the bole. The respecified model is 


$$
\mathrm{V}_{\mathrm{dij}}=\left(\left\{\beta_{0}+\gamma_{0 \mathrm{i}}\right\}+\left\{\beta_{1}+\gamma_{1 \mathrm{i}}\right\} \mathrm{X}_{\mathrm{i}}\right)\left(\frac{\mathrm{t}^{\beta_{2}}+\left(\beta_{3} \mathrm{t}\right)^{\beta_{2}}}{1+\left(\beta_{3} \mathrm{t}\right)^{\beta_{2}}}\right)+\epsilon_{\mathrm{ij}}
$$

where $\gamma_{0} \sim \mathrm{N}\left(0, \sigma_{0}^{2}\right), \gamma_{1} \sim \mathrm{N}\left(0, \sigma_{1}^{2}\right), \operatorname{cov}\left(\gamma_{0}, \gamma_{1}\right)=0 ; \beta_{\mathrm{k}}, \mathrm{k}=0, \ldots, 3$, are fixed parameters; $\epsilon_{\mathrm{ij}} \sim \mathrm{N}\left(0, \sigma^{2}\right)$; and $\mathrm{E}\left[\epsilon_{\mathrm{ij}} \epsilon_{\mathrm{ik}}\right]=0$ for all distinct pairs, $\mathrm{j}, \mathrm{k}=1, \ldots, \mathrm{m}_{\mathrm{i}}$. To complete the specification, we assume observations from distinct trees are mutually uncorrelated. For notational convenience, we re-express (4) as

$$
\mathrm{V}_{\mathrm{dij}}=\mathrm{f}(\mathrm{Q} ; \boldsymbol{\beta}, \gamma)+\epsilon_{\mathrm{ij}}
$$

where $\mathrm{Q}$ represents the set of covariates, $X, d, \mathrm{D} ; \beta=\left[\beta_{0}, \ldots, \beta_{3}\right]^{\prime}$; and $\gamma=\left[\gamma_{0}, \gamma_{1}\right]^{\prime}$.

\section{Methods}

A number of methods have been proposed to fit mixed-effects nonlinear models, notably by Sheiner and Beal (1980), Lindstrom and Bates (1990), Vonesh and Carter (1992), and Davidian and Gallant (1993). In Davidian and Gallant's approach, no parametric assumption is made about the form of the random effects distribution, except that it is smooth. They develop maximum likelihood estimation of the fixed parameters together with the density of the random effects, using a series expansion derived from the smoothness assumption coupled with quadrature to compute the likelihood. Vonesh and Carter consider a model where the random effects enter linearly into $\mathrm{f}(\mathrm{Q} ; \boldsymbol{\beta}, \boldsymbol{\gamma})$, and they use iteratively reweighted least squares to obtain consistent estimators of $\boldsymbol{\beta}$ and the covariance parameters. Davidian and Giltinan (1993) use a similar method to fit heteroscedastic random coefficient models. Another approach is to approximate the marginal distribution of the response vector by expanding $\mathrm{f}(\mathrm{Q} ; \boldsymbol{\beta}, \boldsymbol{\gamma})$ in a first-order Taylor series, as did Sheiner and Beal, and Lindstrom and Bates.

A first-order Taylor expansion of our model, (4), around the values $\boldsymbol{\beta}^{*}, \boldsymbol{\gamma}^{*}$ gives the approximating linear function as

$$
\mathrm{Y}_{\mathrm{dij}} \doteq \mathrm{z}_{\mathrm{ij}}^{\prime} \boldsymbol{\alpha}+\mathbf{w}_{\mathrm{ij}}^{\prime} \tau+\epsilon_{\mathrm{ij}}
$$

where 


$$
\begin{aligned}
Y_{\mathrm{dij}} & =\mathrm{V}_{\mathrm{dij}}-\mathrm{V}_{\mathrm{dij}}^{*} \\
\mathbf{z}_{\mathrm{ij}}^{\prime} & =\left[\frac{\partial \mathrm{f}(\mathrm{Q})}{\partial \beta_{0}^{*}}, \ldots, \frac{\partial \mathrm{f}(\mathrm{Q})}{\partial \beta_{4}^{*}}\right] \\
\boldsymbol{\alpha} & =\boldsymbol{\beta}-\beta^{*} \\
\mathbf{w}_{\mathrm{ij}}^{\prime} & =\left[\frac{\partial \mathrm{f}(\mathrm{Q})}{\partial \gamma_{0}^{*}}, \frac{\partial \mathrm{f}(\mathrm{Q})}{\partial \gamma_{1}^{*}}\right]
\end{aligned}
$$

and

$$
\tau=\gamma-\gamma^{*}
$$

The derivative expressions signify the partial derivative with respect to the indicated parameter, evaluated at the starred value. For notational convenience, we have omitted showing the dependence of $\mathrm{f}(\bullet)$ on $\boldsymbol{\beta}, \boldsymbol{\gamma}$.

When dealing with random effects, a choice has to be made whether to expand around their expected values or around their current BLUPs. Sheiner and Beal (1992) adopted the former; while Lindstrom and Bates (1990) adopted the latter. To date, there is little consensus as to the relative merits of the competing approaches. We examined both.

The expansion of (4) effectively converts it to the linear mixed-model for longitudinal data popularized by Laird and Ware (1982). Therefore, it is comparatively

\begin{tabular}{|c|c|}
\hline$\underline{\text { Step }}$ & Task \\
\hline 0 & Obtain initial values $\boldsymbol{\beta}^{*}$ and $\boldsymbol{\gamma}^{*}$ to start the iteration. \\
\hline 1 & With $\beta^{*}$ and $\gamma^{*}$, evaluate $Y_{\mathrm{dij}}, \mathbf{z}_{\mathrm{ij}}^{\prime}$, $\mathbf{w}_{\mathrm{ij}}^{\prime}$ for each observation. \\
\hline 2 & $\begin{array}{l}\text { Fit (6) with Proc Mixed to obtain estimates of } \boldsymbol{\alpha}, \tau \text {, and } \\
\Delta=\operatorname{cov}(\tau), \text { which are denoted by } \widehat{\alpha}, \widehat{\tau}, \text { and } \widehat{\Delta}\end{array}$ \\
\hline
\end{tabular}
easy to fit owing to the ready availability of computer code tailored to this task. We chose Proc Mixed of SAS and obtained the empirical BLUP of $\gamma$ and the REML estimates of the unknown parameters, in an iterative fashion. Our iterative solution is outlined as follows: 
The matrix and macro programming languages of SAS were used extensively to implement this algorithm, in addition to Proc Mixed.

Finally, we took two approaches to step 0 . In the first, we fitted the fixed-effects version of (4) by nonlinear least squares. The resulting estimates of $\beta$ were used as initial values, $\beta^{*}$, while $\gamma^{*}$ was set to zero. In the second approach, we fitted model (4) using generalized estimating equations (GEE) with an expansion around $\boldsymbol{\gamma}^{*}=\mathrm{E}[\boldsymbol{\gamma}]=\mathbf{0}$ and moment estimation for $\Delta$. We discuss the GEE approach more fully in the next section.

Regardless of the method used in step 0 , the outlined procedure constitutes a nested iterative algorithm in steps 1-3: the outer iteration comprises steps 1 through 3 , the inner iteration step 2.

\section{Generalized Estimating Equations}

An estimating function-based approach (Godambe 1960) has been promoted for the analysis of longitudinal quantal response data by Liang and Zeger (1986). It is based on an estimating function which involves only the first two marginal moments of the response distribution, and it is semi-parametric in that higher-order moments are unspecified. Zeger, Liang and Albert (1988) demonstrated the applicability of this approach to generalized linear mixed models, again focusing on quantal responses. This section briefly discusses how the estimating equations can be utilized for non-linear continuous response models.

The key idea of Zeger, Liang and Albert (1988) is to approximate the marginal moments from the ones conditioned on the random parameters. To do so, we take a first-order Taylor-series expansion of (5) around $\mathrm{E}[\boldsymbol{\gamma}]=\mathbf{0}$. Similarly we approximate the marginal variance by expanding the right hand side of

$$
\operatorname{Var}\left(\mathrm{V}_{d \mathrm{ij}}\right)=\operatorname{Var}\left(\mathrm{E}\left[\mathrm{V}_{d \mathrm{ij}} \mid \boldsymbol{\gamma}\right]\right)+\mathrm{E}\left[\operatorname{Var}\left(\mathrm{V}_{d \mathrm{ij}} \mid \boldsymbol{\gamma}\right)\right]
$$

around $\mathrm{E}[\boldsymbol{\gamma}]$. Consequently, $\mathrm{E}\left[\mathrm{V}_{d \mathrm{ij}}\right] \doteq \mathrm{f}(Q ; \boldsymbol{\beta}, \mathbf{0})$ and 


$$
\operatorname{Var}\left(\mathrm{V}_{d \mathrm{ij}}\right) \doteq \sigma^{2}+\left(\frac{\partial \mathrm{f}(\mathrm{Q} ; \boldsymbol{\beta}, \mathbf{0})}{\partial \boldsymbol{\gamma}}\right) \Delta\left(\frac{\partial \mathrm{f}(\mathrm{Q} ; \boldsymbol{\beta}, \mathbf{0})}{\partial \boldsymbol{\gamma}^{\prime}}\right)=\sigma^{2}+\mathrm{l}_{\mathrm{ij}}^{\prime} \Delta \mathrm{l}_{\mathrm{ij}}
$$

where the derivatives are evaluated at $\mathrm{E}[\boldsymbol{\gamma}]$. Put $\mathrm{Y}_{\mathrm{i}}$ and $\boldsymbol{\mu}_{\mathrm{i}}$ for the approximated mean and expectation $\left(\mathrm{m}_{\mathrm{i}} x 1\right)$ vectors, and $\mathrm{V}_{\mathrm{i}}$ for the $\left(\mathrm{m}_{\mathrm{i}} \times \mathrm{m}_{\mathrm{i}}\right)$ covariance matrix for the $\mathrm{i}^{\text {th }}$ subject, and let $\mathbf{P}_{\mathrm{i}}=\partial \boldsymbol{\mu}_{\mathrm{i}} / \partial \beta$ be the $\left(\mathrm{m}_{\mathrm{i}} \times 4\right)$ gradient matrix. The generalized estimating equations for $\beta \mid \hat{\gamma}$ become

$$
\mathrm{U}(\boldsymbol{\beta}, \widehat{\gamma}, \mathrm{Y})=\sum_{\mathrm{i}=1}^{\mathrm{n}} \mathrm{P}_{\mathrm{i}}^{\prime} \widehat{\mathrm{V}}_{\mathrm{i}}^{-1}\left(\mathrm{Y}_{\mathrm{i}}-\boldsymbol{\mu}_{\mathrm{i}}\right)=\mathbf{0}
$$

These equations are solved iteratively, and in this application we chose a NewtonRaphson algorithm with Fisher scoring. Since the estimates $\widehat{\beta}$ depend on $\operatorname{Var}(\boldsymbol{\gamma})$, and because no distributional assumption was made, a moment estimator is used to update $\widehat{\Delta}$ after each iteration. The structure of $\mathrm{V}_{\mathrm{i}}$ suggests the following estimators

$$
\begin{aligned}
& \widehat{\sigma}^{2}=\frac{1}{n} \sum_{\mathrm{i}=1}^{\mathrm{n}}\left(\mathrm{Y}_{\mathrm{i}}-\widehat{\boldsymbol{\mu}}_{\mathrm{i}}\right)^{\prime} \mathrm{V}_{\mathrm{i}}^{-1}\left(\mathrm{Y}_{\mathrm{i}}-\widehat{\boldsymbol{\mu}}_{\mathrm{i}}\right) \\
& \widehat{\Delta}=\frac{1}{\mathrm{n}} \sum_{\mathrm{i}=1}^{\mathrm{n}}\left(\mathrm{L}_{\mathrm{i}}^{\prime} \mathrm{L}_{\mathrm{i}}\right)^{-1} \mathbf{L}_{\mathrm{i}}^{\prime}\left(\left(\mathrm{Y}_{\mathrm{i}}-\widehat{\boldsymbol{\mu}}_{\mathrm{i}}\right)\left(\mathrm{Y}_{\mathrm{i}}-\widehat{\boldsymbol{\mu}}_{\mathrm{i}}\right)^{\prime}-\widehat{\sigma}^{2} \mathrm{I}\right) \mathbf{L}_{\mathrm{i}}\left(\mathrm{L}_{\mathrm{i}}^{\prime} \mathrm{L}_{\mathrm{i}}\right)^{-1} .
\end{aligned}
$$

Following the main result in Liang and Zeger (1986), $\widehat{\beta}$ will be asymptotically unbiased and Gaussian distributed, provided $\widehat{\Delta}$ and $\sigma^{2}$ are estimated consistently. At convergence of the algorithm, solutions for the random effects are obtained as in the full parametric implementation.

As an estimation method for step 0, nonlinear least squares produces only estimates of the fixed effect parameters. GEE, as an alternative, provide these, plus solutions for the random terms in the model, and the variance-covariance matrix, $\Delta$. If the GEE estimates and solutions are reasonable, the following steps 1-3 can be expected to converge more rapidly and more reliably than when using solely the fixed effects estimates of nonlinear least squares.

The generalized estimating equations account for the serial dependency in the data and individualize the model fit through the BLUP's. If $\widehat{\Delta}$ estimates $\Delta$ well, the estimates and solutions will not differ much from the full parametric implementation. As is always the case with moment estimators, this depends heavily on the sample size. Asymptotically, the semi-parametric and the parametric approach are equivalent. 
Thus, provided sample sizes are not too small, GEE constitutes an analytical method in its own right that meets the goals of this investigation. Since $\widehat{\Delta}$ is a rather simple estimator, the algorithm is computationally much less demanding than a maximization of a likelihood function with respect to the elements of $\Delta$.

\section{Results}

The trees profiled in Figures 1 and 2 were two of 39 trees which were felled and measured for the purpose of developing a bole-volume prediction equation for sweetgum in the East Texas region. Tree heights $(\mathrm{H})$ ranged from 59 to 107 feet, averaging 91 feet; tree basal diameters (D) ranged from 5.8 to 29.7 inches, averaging 16.8 inches; and their total bole volumes $\left(\mathrm{V}_{0}\right)$ ranged from 6 to $201 \mathrm{ft}^{3}$, averaging $73 \mathrm{ft}^{3}$. The outside-bark diameter of each stem was measured at 3 foot intervals along the felled stem and the volume of each three-foot section was computed as the product of its length with its average cross-sectional area. There was an average of 24 bole-diameter measurements per tree, yielding 951 measurements, in toto.

The fixed-effects version of (4) was fitted to benchmark the anticipated improvement offered by the inclusion of one or more random parameters in the model. When (4) was fitted with fixed effects only, $-2 \mathrm{~L}_{\mathrm{R}}=7271$, where $\mathrm{L}_{\mathrm{R}}$ denotes the observed REML log-likelihood. For this model, $\widehat{\sigma}^{2}=120$, and the elements of $\beta$ were all estimated to be clearly significant (see Table 1 ). The deficiencies of this model become apparent, however, when the cumulative volume profiles predicted by it are compared to the empirical profiles. For the two trees displayed earlier, Figure 3 shows the superimposed profiles. Evidently, these two trees accrete more volume in the lower portion and less volume in the upper portion of the bole (above breast height) than the average tree in the sample. In forestry parlance, this phenomenon is a result of differences in tree form. For these two trees, the fitted equation systematically underpredicts volume in the very lowest portion of the bole, which may be of little consequence because prediction of bole volume in these lower reaches of the bole is rarely required. However, the systematic overprediction of volume to merchantably small diameter limits in the upper portion of the bole is consequential and worrisome.

The data did not support the inclusion of both $\gamma_{0}$ and $\gamma_{1}$ jointly in (4). When $\gamma_{0}$ was included and $\gamma_{1}$ was omitted, $-2 \mathrm{~L}_{\mathrm{R}}=6510$ under a subject-specific expansion of $f(Q)$. The cumulative volume profiles predicted by this model are shown in Figure 4, again for the same two trees. The improvement in model performance by inclusion of a random intercept is striking.

Similar improvement was noted when a population-average expansion of $f(Q)$ was 
used with a random intercept, and when the model was specified with $\gamma_{0}$ omitted and $\gamma_{1}$ included. Based on the results exhibited in Table 1 , it is arguable whether any of the random parameter specifications is superior to the others.

The above results were obtained with both techniques for obtaining initial values (step 0 of the computing algorithm). However the initial values obtained from the GEEs were striking in that they were nearly identical to the final estimates obtained at convergence (step 4). Indeed, the cumulative volume profiles from the GEE fit of the model overlays the fully parametric solutions so much that the two profiles are indistinguishable when graphed. This indicates that even with only 39 trees the moment estimator in the GEE implementation performed well. If prediction is the main purpose of the data analysis and the variances of the random terms are in the interior of the parameter space, GEE's alone are fully satisfactory, thereby reducing computing time by more than $70 \%$ as compared to the full likelihood implementation. For the model with a random slope, $\operatorname{Var}\left(\gamma_{1}\right)$ is very small and the moment estimator performs poorer at the boundary of the parameter space.

\section{Summary Discussion}

This work was motivated by a concern that typical models to predict bole volume to any stipulated upper-bole diameter could be improved 1) by estimating the parameters jointly; 2) by fitting an equation form that mimicked the empirical cumulative volume profiles better, at least by exhibiting an inflection which typifies many growth curves; 3 ) and by accounting for inter-tree differences and/or intra-tree similarities. The modeling strategy presented here appears to have accomplished all three tasks.

Follow-up work will require that we apply this strategy more broadly, in order to ensure that the advantages apparent when fitting sweetgum data are realized when fitting volume equations to data from other species.

Future work may focus, too, on improving the $\mathrm{R}$ term of the model in order to rectify the lack-of-fit for lower-bole volumes that is evident in Figure 4. We speculate that this lack-of-fit derives chiefly from the fact that at breast height, $d=\mathrm{D}$, which forces $\mathrm{R}=0=\mathrm{E}\left[\mathrm{V}_{\mathrm{d}}\right]$. It may be preferable to stipulate $\mathrm{R}$ in such a way that ensures $\mathrm{E}\left[\mathrm{V}_{\mathrm{d}}\right]=0$ only at $d=\mathrm{D}_{\mathrm{S}}$, where $\mathrm{D}_{\mathrm{S}}$ is bole diameter at stump height. 


\section{References}

Amateis, R. L. and Burkhart, H. E. (1987). Cubic-foot volume equations for loblolly pine trees in cutover, site-prepared plantations. Southern Journal of Applied Forestry, 11, 190-192.

Davidian, M. and Gallant, A. R. (1993) The nonlinear mixed effects model with a smooth random effects density. Biometrika, 80, 475-488.

Davidian, M. and Giltinan, D. M. (1993) Some simple methods for estimating intraindividual variability in nonlinear mixed effects models. Biometrics, 49, $59-73$.

Diggle, P. J. (1988). An approach to the analysis of repeated measurements. Biometrics, 44, 959-971.

Godambe, V.P. (1960). An optimum property of regular maximum likelihood estimation. The Annals of Mathematical Statistics, 31, 1208-1211

Gregoire, T. G., Schabenberger, O., and Barrett, J. P. (1995). Linear modelling of irregularly spaced, unbalanced, longitudinal data from permanent plot measurements. Canadian Journal of Forest Research (in press).

Jones, R. H. (1990). Serial correlation or random subject effects? Communications in Statistics - Simulation, 19, 1105-1123.

Laird, N. M. and Ware, J. H. (1982). Random-effects models for longitudinal data. Biometrics, 38, 963-974.

Liang, K.-Y. and Zeger, S.L. (1986). Longitudinal analysis using generalized linear models. Biometrika, 73, 13-22

Lindstrom, M. J. and Bates, D. M. (1990). Nonlinear mixed effects models for repeated measures data. Biometrics, 46, 673-687.

Morgan, P. H., Mercer, L. P., and Flodin, N. W. (1975). General model for nutritional responses of higher organisms. Proceedings of the National Academy of Science, U. S. A., 72, 4327-4331.

Seber, G. A. F. and Wild, C. J. (1989). Nonlinear Regression. John Wiley \& Sons: New York.

Sheiner, L. B. and Beal, S. L. (1980). Evaluation of methods for estimating population pharmacokinetic parameters. I. Michaelis-Menton model: Routine clinical pharmacokinetic. Journal of Pharmacokinetics and Biopharmaceutics, 8, 553-571.

Vonesh, E. F. and Carter, R. L. (1992). Mixed-effects nonlinear regression for unbalanced repeated measures. Biometrics, 48, 1-17.

Zeger, S.L., Liang, K.-Y., and Albert, P.S. (1988). Models for Longitudinal Data: A Generalized Estimating Equation Approach. Biometrics, 44, 1049-1060 
Table 1. Parameter estimates for model (4) under various specifications of fixed and random parameters. Estimated standard errors appear in parentheses.

\begin{tabular}{|c|c|c|c|c|c|c|c|c|}
\hline Specification & $-2 \mathrm{~L}_{\mathrm{R}}$ & $\beta_{0}$ & $\beta_{1}^{*}$ & $\beta_{2}$ & $\beta_{3}$ & $\sigma^{2}$ & $\sigma_{0}^{2}$ & $\sigma_{1}^{2 * *}$ \\
\hline Fixed effects & 7271 & $\begin{array}{l}6.06 \\
(.783)\end{array}$ & $\begin{array}{l}2.10 \\
(.024)\end{array}$ & $\begin{array}{l}2.03 \\
(.086)\end{array}$ & $\begin{array}{l}4.83 \\
(.098)\end{array}$ & 120 & - & - \\
\hline $\begin{array}{c}\gamma_{0}, \text { subject- } \\
\text { specific }\end{array}$ & 6510 & $\begin{array}{l}5.14 \\
(2.77)\end{array}$ & $\begin{array}{l}2.15 \\
(.071)\end{array}$ & $\begin{array}{l}2.10 \\
(.054)\end{array}$ & $\begin{array}{l}4.79 \\
(.058)\end{array}$ & 47 & 132 & - \\
\hline $\begin{array}{c}\gamma_{0}, \text { population- } \\
\text { averaged }\end{array}$ & 6513 & $\begin{array}{l}5.19 \\
(2.79)\end{array}$ & $\begin{array}{l}2.17 \\
(.072)\end{array}$ & $\begin{array}{l}2.09 \\
(.054)\end{array}$ & $\begin{array}{l}4.70 \\
(.058)\end{array}$ & 47 & 135 & - \\
\hline $\begin{array}{c}\gamma_{1}, \text { subject- } \\
\text { specific }\end{array}$ & 6467 & $\begin{array}{l}2.32 \\
(.948)\end{array}$ & $\begin{array}{l}2.29 \\
(.077)\end{array}$ & $\begin{array}{l}2.10 \\
(.054)\end{array}$ & $\begin{array}{l}4.79 \\
(.058)\end{array}$ & 47 & - & .911 \\
\hline $\begin{array}{c}\gamma_{1} \text {, population- } \\
\quad \text { averaged }\end{array}$ & 6470 & $\begin{array}{l}2.35 \\
(.956)\end{array}$ & $\begin{array}{l}2.30 \\
(.078)\end{array}$ & $\begin{array}{l}2.09 \\
(.052)\end{array}$ & $\begin{array}{l}4.70 \\
(.055)\end{array}$ & 47 & - & .927 \\
\hline$\gamma_{0}$, GEE only & - & $\begin{array}{l}5.19 \\
(2.70)\end{array}$ & $\begin{array}{l}2.16 \\
(.069)\end{array}$ & $\begin{array}{l}2.09 \\
(.054)\end{array}$ & $\begin{array}{l}4.70 \\
(.058)\end{array}$ & 47 & 127 & - \\
\hline$\gamma_{1}$, GEE only & - & $\begin{array}{l}2.33 \\
(.960)\end{array}$ & $\begin{array}{l}2.30 \\
(.079)\end{array}$ & $\begin{array}{l}2.09 \\
(.052)\end{array}$ & $\begin{array}{l}4.69 \\
(.055)\end{array}$ & 46 & - & .955 \\
\hline
\end{tabular}

* Values in this column have been multiplied by $10^{3}$

${ }^{* *}$ Values in this column have been multiplied by $10^{6}$ 

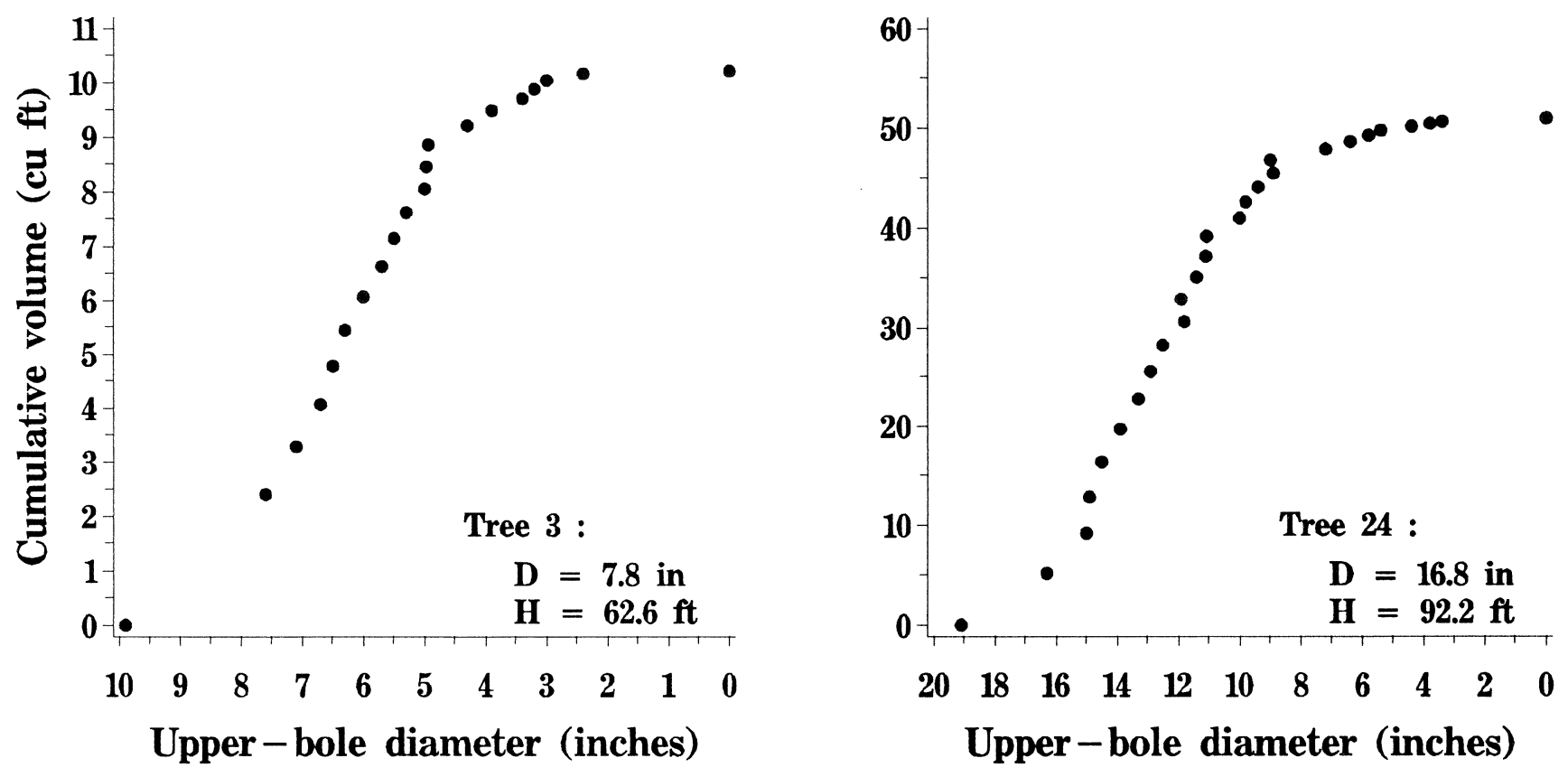

\section{Figure 1. Cumulative volume profiles of two sweetgum tree boles.}




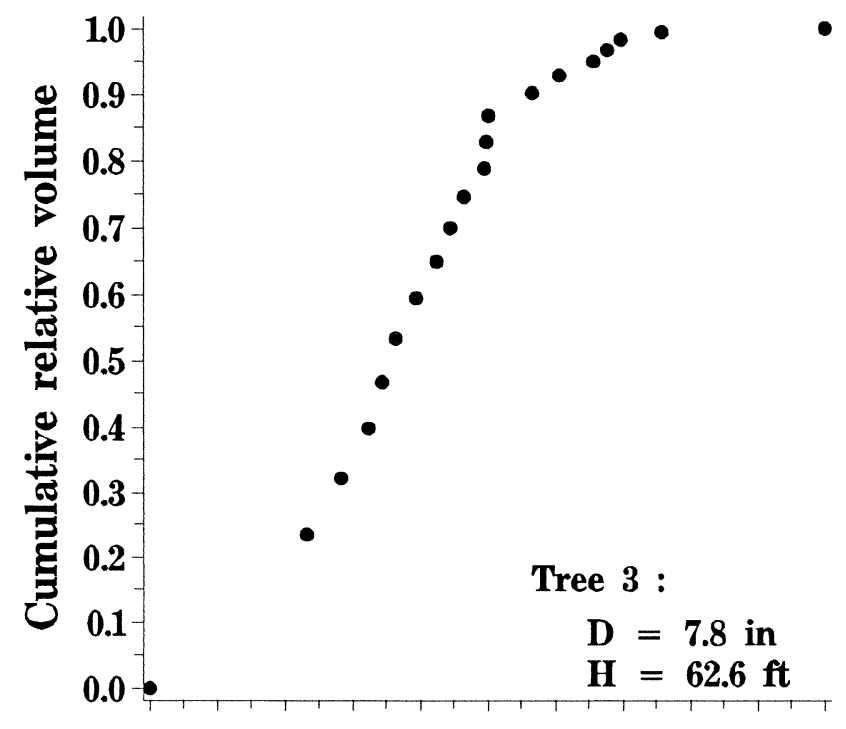

$\begin{array}{lllllllllll}1.0 & 0.9 & 0.8 & 0.7 & 0.6 & 0.5 & 0.4 & 0.3 & 0.2 & 0.1 & 0.0\end{array}$ Relative diameter

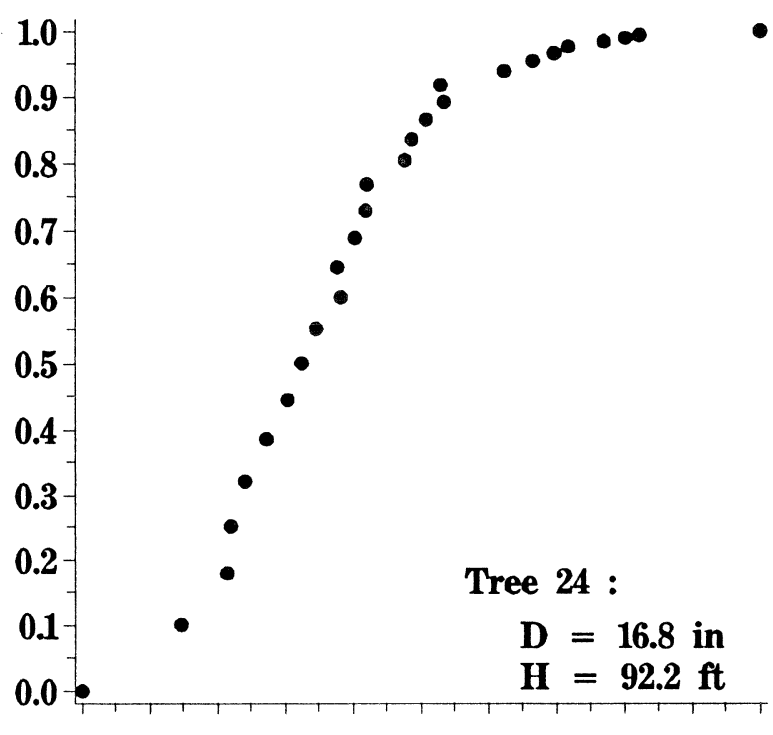

$\begin{array}{lllllllllll}1.0 & 0.9 & 0.8 & 0.7 & 0.6 & 0.5 & 0.4 & 0.3 & 0.2 & 0.1 & 0.0\end{array}$ Relative diameter

\section{Figure 2. Cumulative relative volume profiles of two sweetgum tree boles.}



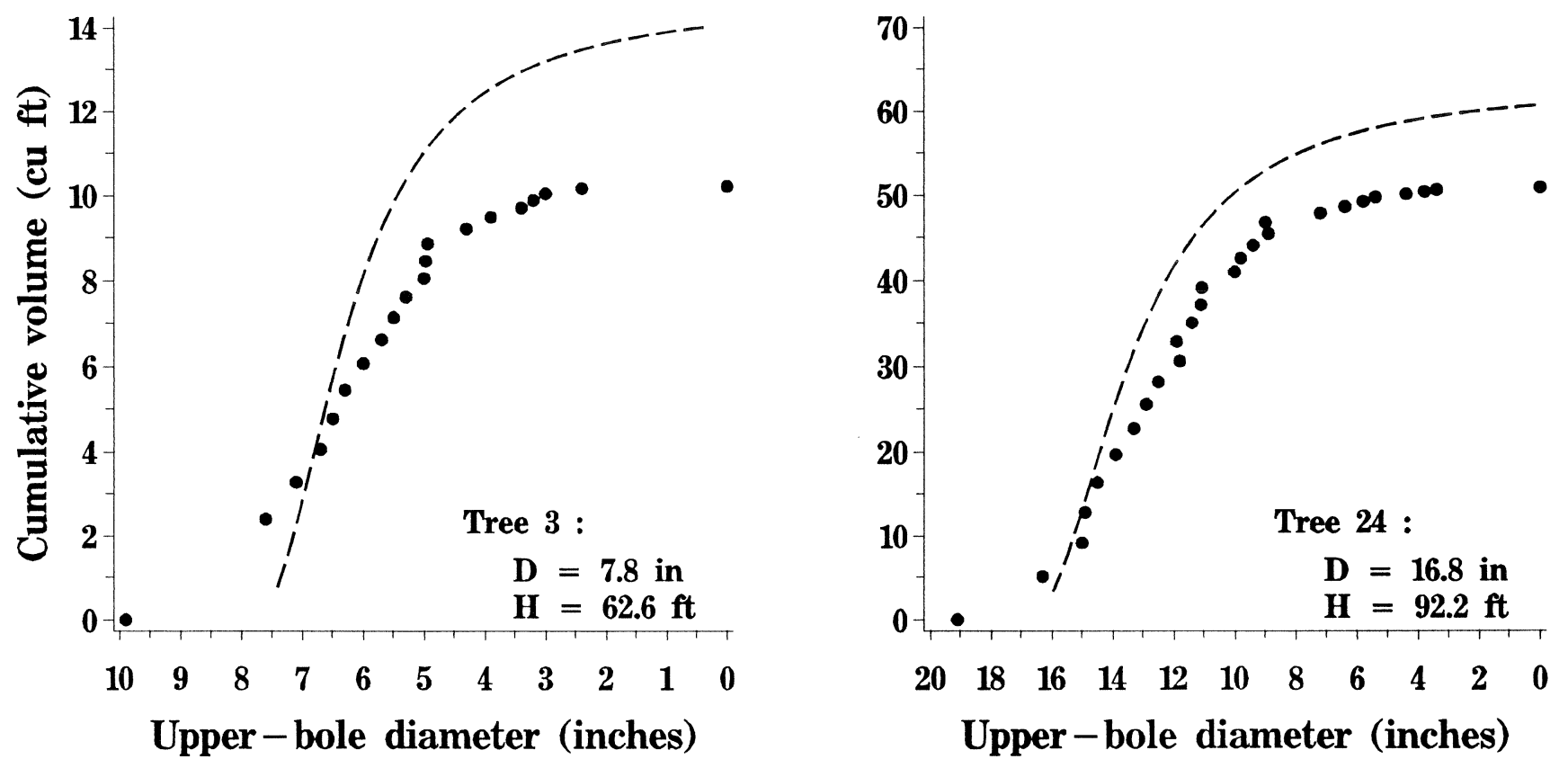

Figure 3. Cumulative volume profiles of two sweetgum tree boles. The bullets trace the empirical profiles, and the dashed lines trace the profiles predicted from the fixed-effects version of model (4). 

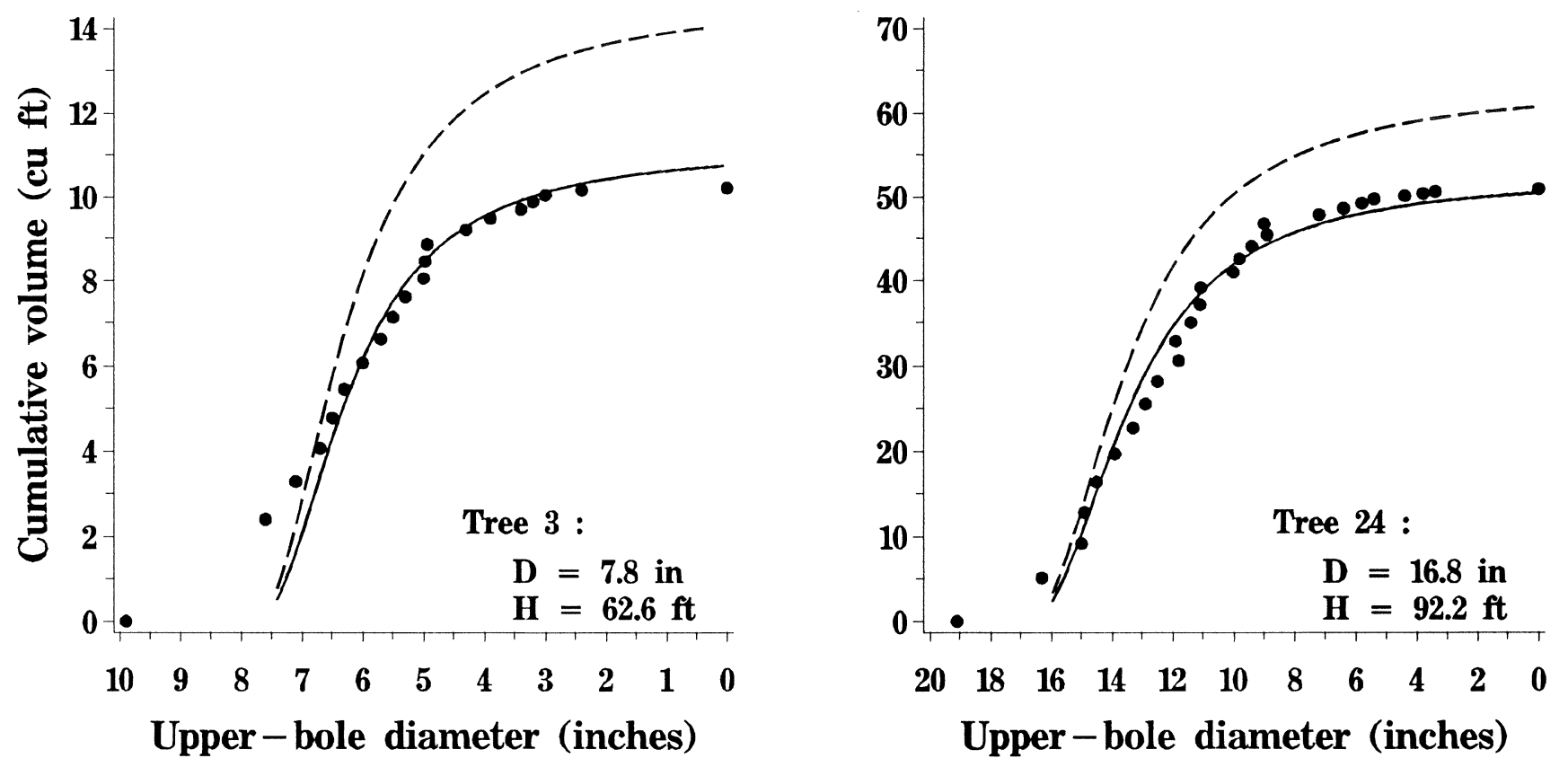

Figure 4. Cumulative volume profiles of two sweetgum tree boles. The bullets trace the empirical profiles, the dashed lines trace the profiles predicted from the fixed-effects version of model (4), and the solid lines trace the profiles predicted from the randomintercept version of model (4). 